\title{
Gratitud y esperanza
}

\author{
Gratitude and hope \\ Gratidão e esperança
}

\author{
Angélica María Pérez Cano* \\ https://doi.org/10.35454/rncm.v4supl1.344
}

Como decía Dalai Lama: "La raíz de todo bien reposa en la tierra de la gratitud". Quiero aproximarme a ustedes para darles las gracias, gracias por la confianza depositada en mí y en la junta directiva para continuar con el gran trabajo de liderar la asociación más grande del país en nutrición (la Asociación Colombiana de Nutrición Clínica $[\mathrm{ACNC}]$ ), estamos convencidos de que tenemos todas las facultades para liderarla. Haremos lo posible por continuar enalteciendo la Asociación a nivel nacional e internacional, que la recibimos el pasado 19 de julio muy bien posicionada. Desde ese mismo día, la junta directiva inició un trabajo lleno de expectativas y de buenos deseos para la misión encomendada. Ya hace 10 años me aproximé a la ACNC esperanzada en poder contribuir con esta como miembro activo, luego como parte de la junta directiva y ahora a la cabeza de ella, especialmente en esta época tan difícil que estamos atravesando.

Nuestro plan de acción presentado en la pasada asamblea del 13 de mayo de 2021 busca cumplir con los objetivos y la misión de la ACNC, cuyo planteamiento se basa en 4 ejes: educación, investigación, vinculación y adaptación.

En el primer eje, la educación, se implementarán actividades acordes a las necesidades de nuestros afiliados, dirigidas a la comunidad científica, a los pacientes, sus cuidadores y a la población en general. Estamos convencidos de que la educación es la base del desarrollo de las personas y las sociedades, y por ello continuaremos trabajando con gran esfuerzo en este eje.

En el segundo eje, la investigación, queremos dar un mayor apoyo a los grupos de investigación regionales,

*Correspondencia: Angélica María Pérez Cano.

presidencia@nutriclinicacolombia.org motivando a nuestros asociados a investigar y publicar en nuestra revista. La generación del conocimiento es un aspecto clave en el progreso de las ciencias, y el rol de las sociedades científicas es apoyarlo. También continuaremos con la construcción y divulgación de consensos para presentar a instancias gubernamentales.

El tercer eje es la vinculación, a través del cual queremos impulsar la participación de nuestros afiliados en los comités interdisciplinarios que hasta ahora no ha sido posible activar; buscaremos acercamientos con diferentes asociaciones que tengan relación directa con la terapia médica nutricional y puedan aportar para una mejor praxis. También buscaremos alianzas éticas, responsables y con la mayor transparencia con la industria farmacéutica y de alimentos con el interés de educar más a sus consumidores.

El cuarto eje es la adaptación, el cual implica adaptarnos al contexto actual de la pandemia de la enfermedad por coronavirus de 2019 (COVID-19); para ello queremos activar nuestras actividades educativas híbridas mientras las condiciones lo permitan, aplicando las nuevas herramientas tecnológicas que demanda este momento.

Por último, queremos aportar al bienestar mental y físico de nuestros afiliados escuchándolos siempre y proponiendo actividades que precisamente les ayuden a manejar la presión y sobrecarga laboral que tenemos que vivir a causa de la atención desbordada de pacientes con COVID-19.

Hoy más que nunca la unión y el trabajo en equipo es la solución. Hago un llamado a la reintegración; los esperamos con los brazos abiertos llenos de esperanza por un mejor mañana y que pronto podamos volver a abrazarnos con el planteamiento de reiniciar activida- 
des presenciales. Siempre recuerden que la $\mathrm{ACNC}$ es de todos y para todos.

Al comprender que el cuidado nutricional es un proceso y que la terapia médica nutricional se debe entender en términos de dignidad de la persona enferma, es obligatorio profundizar los principios y valores éticos. Es por eso que este suplemento pretende revisar las relaciones entre cuidado y responsabilidad, los dilemas éticos en la investigación en salud y nutrición, y el diálogo interdisciplinario para una ética armónica de la Declaración de Cartagena, además de que se publica por primera vez el código de ética del nutricionista clínico.

Agradezco a la nutricionista Lina María Sierra por su importante contribución como editora invitada en este número. Espero que lo disfruten.

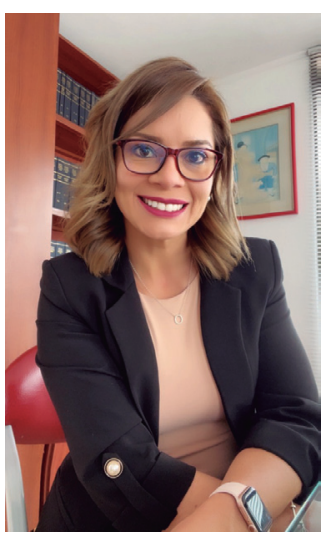

Angélica María Pérez Cano

Nutricionista Dietista, Universidad Nacional de Colombia

Especialista en Salud Ocupacional

Maestría (c) en Nutrición Clínica

Profesora certificada en el curso Long Life Learning (LLL) de la

Sociedad Europea de Nutrición Clínica y Metabolismo (ESPEN)

Profesora certificada en el Curso Interdisciplinario de Nutrición

Clínica (CINC) de Federación Latinoamericana de Terapia

Nutricional, Nutrición Clínica y Metabolismo (FELANPE)

Experiencia en docencia universitaria

Jefe del departamento de nutrición clínica, Hospital Infantil

Universitario San José, Bogotá

Coordinadora del Nacional Nutrition Day, Colombia

Presidente de la ACNC, 2021-2023. 